
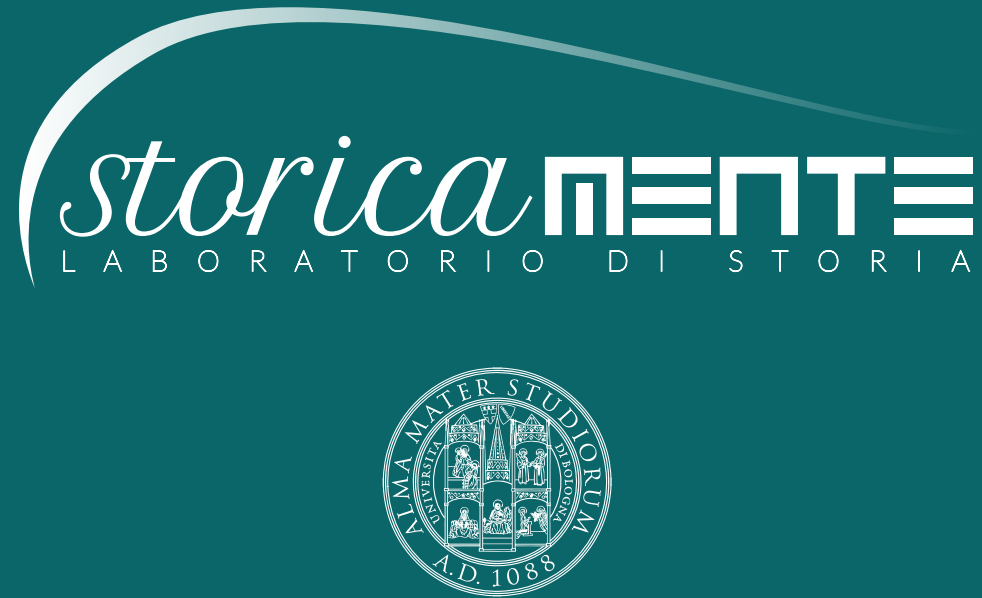

ALMA MATER STUDIORUM

Università di Bologna

Dipartimento di Storia Culture Civiltà

BIBLIO

TECA 


\section{STORICAMENTE.ORG}

\section{Laboratorio di Storia}

Maria Pia Casalena

Domenico Maria Bruni, "Con regolata indifferenza, con attenzione costante». Potere politico e parola stampata nel Granducato di Toscana (1814-1847)"

Numero 12 - 2016

ISSN: $1825-411 \mathrm{X}$

Art. 34

pp. 1-3

DOI: $10.12977 /$ stor651

Editore: BraDypUS

Data di pubblicazione: 24/03/2017

Sezione: Biblioteca 


\title{
Domenico Maria Bruni, " "Con regolata indifferenza, con attenzione costante». Potere politico e parola stampata nel Granducato di Toscana (1814- 1847)"'
}

\author{
MARIA PIA CASALENA \\ Univ. Bologna, Dipartimento di Storia Culture Civiltà
}

Domenico Maria Bruni, "“Con regolata indifferenza, con attenzione costante». Potere politico e parola stampata nel Granducato di Toscana (18141847)", Milano, FrancoAngeli, 2015, 356 pp.

In apertura Bruni si misura con i due riferimenti storiografici in qualche modo obbligatori: da una parte il Berengo degli Intellettuali e librai, dall'altra il Chiavistelli teorico del Granducato di Toscana della prima metà del XIX secolo come «Stato senza pubblico». Ancor di più, l'a. opera una aggiornata revisione del paradigma habermasiano sull'opinione pubblica, che certamente potrà giovarsi di studi come questo il quale, muovendosi per la prima volta dopo alcuni tentativi pionieristici sul terreno spinoso e scivoloso delle fonti "ufficiali", riesce a ricostruire una interessante "storia istituzionale della cultura". Al centro dell'attenzione è la censura granducale dei decenni risorgimentali, o meglio: al centro ci sono i censori, ancora parecchio autonomi e talvolta discordi nella loro azione malgrado un - parzialissimo - tentativo di accentramento. Emerge una realtà assai vivace e aperta al contraddittorio: da una parte stanno certamente le esigenze di controllo e limitazione 
dell'opinione pubblica - in campo politico ma non solo; dall'altra, però, stanno le infinite mediazioni, gli abili raggiri della norma, i veri e propri escamotage, e non da ultimi, alcuni fruttuosi tentativi di conciliazione concertati tra quelli che si rivelano funzionari mancati e gli operatori di un settore sempre più significativo per l'economia statale e considerati, tutto sommato, con un occhio di riguardo dai governi.

Bruni annovera fonti provenienti da tanti archivi, che incrocia con altri materiali al punto da riuscire a rievocare nel suo concreto funzionamento le ragioni per cui il Granducato post-napoleonico fu a lungo "lo Stato più liberale d'Italia", pur non mancando ripercussioni degli eventi nazionali e internazionali (dalle Tre Gloriose ai moti del 1831 nel vicino Stato Pontificio) ed episodi invero incresciosi come quello, celeberrimo, che portò alla chiusura della "Antologia» di Vieusseux. Poi, una crescita per molti versi convulsa e inarrestabile di una produzione (e importazione) libraria sempre più declinata in senso liberal-nazionale, fino a giungere alla legge prequarantottesca che ormai riteneva opportuno spostare l'attenzione - e il controllo - dalle opere in volume ai giornali. In mezzo, si segnalano il singolare permissivismo del censore che pure operava nella Livorno guerrazziana, i tanti tomi usciti nonostante tutto con indicazione "Italia" e quindi non addebitabili al lassismo delle autorità lorenesi, $\mathrm{i}$ (pochi, in verità) tentativi di revisione e aggiustamento testuale che pure contribuivano a testimoniare di una premura che faceva pur sempre i conti con le esigenze di tutela del settore. Qualche figura si staglia sulla scena per interi decenni, allineandosi alla fotografia dell'élite di governo granducale dell'età della Restaurazione; qualche altra fa una comparsa più sfuggente: ma tutti, per quanto spesso in abiti talari, tennero a distinguere sempre e comunque tra preservazione della morale cattolica e mera acquiescenza nei riguardi della Curia romana. Così come il rispetto doveroso dell'assetto viennese non andò alla fine esente da qualche provocazione che i censori fecero passare, una volta adoperati i necessari accorgimenti.

Alla fine della lettura di questo libro, auspichiamo una serie di nuovi 
studi sulle censure preunitarie che contribuiscano a gettare miglior luce sulle regole effettive del confronto tra operatori del mondo della parola stampata e portavoce del ritorno all'ordine. Bruni non manca di toccare aspetti a lungo sottovalutati, come la maggior liceità che si accordava alle opere stampate "all'estero" o comunque a quelle semplicemente "importate" nello Stato. Questo e altri rilievi possono concorrere alla ridefinizione di un campo nel quale editori (e librai e semplici tipografi) e nascenti "intellettuali" trovavano il modo di anticipare quella che in altra sede è stata definita l'uscita dall'ancien régime della cultura. Al contempo, Bruni riesce con la sua narrazione a mantenere fede alle premesse indicate in sede metodologica e storiografica. E se la vicenda del Granducato lorenese continua a segnalarsi per una forte eredità settecentesca rivitalizzata dal crollo delle istituzioni francesi, nondimeno l'irrompere della temperie risorgimentale riuscì a scompaginare antiche certezze e sperimentati dispositivi di controllo. La narrazione si chiude alla vigilia della concessione della Costituzione. Seguiranno, come ben sappiamo, i traumi quarantotteschi e le manovre - queste sì, più incisive - di accentramento messe in atto negli anni Cinquanta. Se il percorso inaugurato da Bruni potesse misurarsi in un prossimo futuro anche con questa stagione troppo spesso soffocata dall'ingombrante etichetta di "decennio di preparazione" e preservare quelle che continuarono a essere le peculiarità toscane, potremmo aggiungere un nuovo tassello a quella "storia istituzionale della cultura" così abilmente - e piacevolmente - avviata dall'a. con questa sua ricognizione nel Vormärz. 